\title{
The Phytoalexin Resveratrol Ameliorates Ochratoxin A Toxicity in Human Embryonic Kidney (HEK293) Cells
}

\author{
Shanel Raghubeer, ${ }^{1}$ Savania Nagiah, ${ }^{1}$ Alisa Phulukdaree, ${ }^{2}$ and Anil Chuturgoon ${ }^{1 *}$ \\ ${ }^{1}$ Discipline of Medical Biochemistry, School of Laboratory Medicine and Medical Sciences, College of Health \\ Sciences, University of KwaZulu-Natal, Durban 4041, South Africa \\ ${ }^{2}$ Department of Physiology, School of Medicine, Faculty of Health Sciences, University of Pretoria, Pretoria, South \\ Africa
}

\begin{abstract}
Ochratoxin A (OTA) is a nephrotoxic mycotoxin produced by Aspergillus and Penicillium fungi. It contaminates human and animal food products, and chronic exposure is associated with renal fibrosis in humans (Balkan endemic nephropathy). Resveratrol, a phytoalexin, possesses anti-cancer and antioxidant properties. We investigated the mechanism of cellular oxidative stress induced by 0TA, and the effect of resveratrol in human embryonic kidney (HEK293) cells over 24 and $48 \mathrm{~h}$. Cells were exposed to 0TA [IC50 = $1.5 \mu \mathrm{M}(24 \mathrm{~h})$ and $9.4 \mu \mathrm{M}$ ( $48 \mathrm{~h}$ ) determined using MTT assay] and $25 \mu \mathrm{M}$ resveratrol. Glutathione was quantified by luminometry and gene expression of Nrf2 and 0GG1 was determined by qPCR. Protein expression of Nrf2, LonP1, SIRT3, and pSIRT1 was assessed by Western blot, DNA damage (comet assay), and intracellular reactive oxygen species (flow cytometry). At $24 \mathrm{~h}$, resveratrol increased mRNA expression of the DNA repair enzyme, 0GG1 $(P<0.05)$, whereas 0TA and 0TA+resveratrol significantly decreased 0GG1 expression $(P<0.05)$. 0GG1 expression increased during 48 -h exposure to resveratrol and OTA+resveratrol $(P<0.05)$. Comet tail lengths doubled in 48-h OTA-treated cells, whereas at both time periods, OTA+resveratrol yielded shorter comet tails $(P<0.0001)$. During 24 - and 48-h exposure, OTA, resveratrol, and 0TA+resveratrol significantly decreased mRNA expression of Nrf2 $(P<0.05)$. Luminometry analysis of GSH revealed an increase by 0TA+resveratrol for 24 and $48 \mathrm{~h}$ $(P<0.05$ and $P<0.001$, respectively). Western blot analysis showed decreased Nrf2 protein expression during 24-h exposure, but increased Nrf2 expression during $48 \mathrm{~h}$. LonP1 protein expression increased during 24-h exposure to 0TA $(P<0.05)$ and 0TA+resveratrol $(P<0.0011)$ and during 48-h exposure to resveratrol $(P<0.0005)$.
\end{abstract}

\section{KEY WORDS: RESVERATROL; OCHRATOXIN A; OXIDATIVE STRESS; LONP1; HEK293 CELLS}

0 chratoxin A (OTA) is a common contaminant of foods, such as grains, fruit, and animal feed [Marin-Kuan et al., 2008]. It is ubiquitously produced by fungal species of Aspergillus and Penicillium, specifically Aspergillus ochraceus [Schilter et al., 2005]. Rural populations in developing countries rely heavily on grains as a staple source of sustenance; many of these communities lack proper storage facilities for harvested grains; this leads to increased fungal contamination and potentially increased production of OTA [Bankole et al., 2006]. OTA was first discovered in South Africa (SA) in 1965 (van der Merwe et al., 1965) and has since been found in food sources around the world [Jonsyn-Ellis, 2012]. Although first discovered in SA, there is still little documented information on OTA mycotoxicosis in SA. Understanding the mechanism of OTA toxicity is particularly important for African countries as grains, such as cassava and maize, contribute to a large part of the daily sustenance for a high percentage of the population [Jonsyn-Ellis, 2012].

Microorganisms in the gastrointestinal tract (GIT) hydrolyze 0TA to the less toxic by-product, Ochratoxin $\alpha(0 \mathrm{~T} \alpha)$ [Hohler et al., 1999], which is then excreted via the liver and kidney [Cheng et al., 2013]. Exposure to high levels of OTA has been linked to renal dysfunction and tumourigenesis in humans [Özçelik et al., 2004]. OTA is nephrotoxic and results in destruction of the renal tubular epithelium, causing progressive renal failure [Pfohl-Leszkowicz

Conflict of interest: None.

Grant sponsor: NRF-DAAD Masters Scholarship 2014; Grant sponsor: University of Kwazulu-Natal College of Health Sciences Scholarship 2014.

\footnotetext{
${ }^{*}$ Correspondence to: Prof. Anil A. Chuturgoon.Discipline of Medical Biochemistry and Chemical Pathology, Faculty of Health Sciences, George Campbell Building, Howard College, University of KwaZulu Natal, Durban 4041, South Africa

E-mail: chutur@ukzn.ac.za
} 
and Manderville, 2007]. This disease is particularly prominent in the Balkan regions, such as Bulgaria and Romania, and is known as Balkan endemic nephropathy (BEN) [Pfohl-Leszkowicz and Manderville, 2007]. OTA exerts its toxic effects via a number of mechanisms, the most prominent method is by alteration of the antioxidant potential of the cell [Meyer et al., 2013], resulting in oxidative stress induction, and increased reactive oxygen species (ROS) [Schaaf et al., 2002]. During oxidative stress, nuclear factor-erythroid 2-related factor 2 (Nrf2) dissociates from its inhibitor, Kelch-like ECHassociated protein 1 (Keap-1), translocates into the nucleus, and binds to the antioxidant response element (ARE), resulting in the transcription of proteins associated with the antioxidant defence system [Nguyen et al., 2009]. Therefore, we aimed to investigate the interactions of both 0TA and resveratrol with the Nrf2 antioxidant defence system in cultured human kidney cells.

Resveratrol (3, 4', 5-trihydroxy-trans-stilbene) is a polyphenol found in the skin of injured grapes and some fruit, and is, therefore, commonly present in wine and grape juice [Athar et al., 2007]. Resveratrol, synthesized by plants as a defensive mechanism, is proposed to have antimicrobial, antioxidant, anti-carcinogenic, and anti-inflammatory properties [Athar et al., 2007]. This compound is widely studied and holds great potential in disease treatment. Resveratrol possesses free radical scavenging potential, contributing to its antioxidant capacity [Borra et al., 2005]. The phytoalexin is also known to activate sirtuin 1 (SIRT1), a $\mathrm{NAD}^{+}$-dependent deacetylase known for its ability to modulate transcription of proteins that augment the oxidative stress response, as well as proteins that promote cell survival in times of stress [Borra et al., 2005; Timmers et al., 2012]. These attributes could contribute to the compound's chemo-preventive ability, as well as the ability to diminish cellular damage due to oxidative stress [Baur and Sinclair, 2006]. Both resveratrol and OTA have been found in grapes; therefore, it is important to have an understanding of the dynamic between these two compounds. OTA exposure is widespread throughout Europe, through the ingestion of grape products, such as wine and juice. This is especially prominent in the grapeproducing regions of Italy [Visconti et al., 2008]

The mechanisms of OTA toxicity and the cellular antioxidant response are relatively unknown. This study investigated the cytotoxic effects of OTA on HEK293 cells after 24- and 48-h exposure. Further, the therapeutic effects of resveratrol in both untreated and OTA-treated HEK293 cells were investigated. We believe these results will provide valuable insight into OTA toxicity in human kidney cells, and whether resveratrol can be used as a potential treatment to combat this toxicity.

\section{Materials}

Tissue culture consumables were purchased from Whitehead Scientific (Johannesburg, South Africa). The HEK293 cells were obtained from Highveld Biological (Johannesburg, South Africa). Ochratoxin A and resveratrol were purchased from Sigma-Aldrich (St Louis, MO). Methylthiazoltetrazolium (MTT) salt, phosphate buffered saline (PBS) tablets, and agarose were purchased from Capital Laboratory Supplies (Johannesburg, South Africa). The bicinchoninic acid (BCA) assay kit and tris-chloride were purchased from Sigma-Aldrich. Kits and reagents used for luminometry (GSH-Glo ${ }^{\mathrm{TM}}$ Glutathione Assay kit) were purchased from Promega (Madison, USA). Reagents for qPCR were purchased from Bio-Rad (Hercules, CA) and the primer sequences were purchased from Inqaba Biotechnologies (Pretoria, South Africa). Western blotting reagents (Laemmli sample buffer and chemiluminescent reagents) were obtained from Bio-Rad. Primary antibodies (rabbit anti-Nrf2 (8882), rabbit anti-SIRT3 (C73E7), and rabbit antipSIRT1 (2314L) were purchased from Cell Signaling Technology (Danvers, M0). Rabbit anti-LonP1 (HPA002192-100UL) was purchased from Sigma-Aldrich (St. Louis, MO) and horse-radish peroxidase (HRP)-conjugated secondary antibodies (anti-rabbit IgG) were purchased from Cell Signaling Technology. Proteins were normalized to anti- $\beta$-actin (A3854) from Sigma-Aldrich. All other solvents and salts were purchased from Merck Chemicals (Johannesburg, South Africa). Protein isolation was conducted using Cytobuster ${ }^{\mathrm{TM}}$ (Novagen), supplemented with protease inhibitors (Roche 05892791001) and phosphatase inhibitors (04906837001).

\section{Methods}

\section{CELL CULTURE}

HEK293 cells were cultured in monolayer $\left(10^{6}\right.$ cells per $25 \mathrm{~cm}^{3}$ culture flask). The cells were maintained in complete culture medium [CCM: Dulbecco's minimum essential media (DMEM), 10\% fetal calf serum, $1 \%$ penstrepfungizone, and 1\% L-glutamine] and incubated overnight at $37{ }^{\circ} \mathrm{C}$ in a humidified incubator supplied with $5 \% \mathrm{CO}_{2}$. Cells were washed with $0.1 \mathrm{M}$ PBS. Once flasks were confluent, cells were treated, removed by trypsinisation and agitation, and counted using the trypan blue exclusion assay.

\section{OCHRATOXIN A TREATMENTS}

A stock solution of $200 \mu \mathrm{M}$ OTA was prepared in $60 \%$ dimethyl sulphoxide (DMSO). Cells were treated with a range $(0.25-50 \mu \mathrm{M})$ of concentrations to obtain a half maximal inhibitory concentration $\left(\mathrm{IC}_{50}\right)$ for $24-$ and $48-\mathrm{h}$ incubation times.

\section{METHYLTHIAZOL TETRAZOLIUM (MTT) ASSAY}

Cells were seeded into a 96-well microtiter plate (15,000 cells/well) and allowed to attach overnight. Attached cells were treated with a range of OTA concentrations $(0.25-50 \mu \mathrm{M})$ for 24 and $48 \mathrm{~h}$. Treatment media was removed and replaced with CCM (100 $\mu$ l) and $20 \mu \mathrm{l}$ MTT salt solution ( $5 \mathrm{mg} / \mathrm{ml}$ in PBS). Cells were incubated with the MTT salt solution for $4 \mathrm{~h}$, thereafter the MTT solution was discarded and DMSO $(100 \mu \mathrm{l})$ was added; the cells were incubated with DMSO for $1 \mathrm{~h}$. Absorbance was read using a Bio-Tek MQx200 spectrophotometer at $595 \mathrm{~nm}$ (reference wavelength $655 \mathrm{~nm}$ ). An inhibitory concentration at which $50 \%$ of cell growth was inhibited $\left(\mathrm{IC}_{50}\right)$ was calculated using GraphPad Prism statistical software (version 5).

\section{RESVERATROL TREATMENTS}

Stock solutions of $10 \mathrm{mM}$ resveratrol were prepared in 100\% DMSO. Preliminary assays were carried out to determine the optimal resveratrol concentrations for all subsequent treatments. Cells were treated with $25 \mu \mathrm{M}, 50 \mu \mathrm{M}$, and $100 \mu \mathrm{M}$ resveratrol during pre-, 
post- and co-0TA treatments for $24 \mathrm{~h}$, respectively. Flow cytometry was used to observe which resveratrol concentration greatly decreased the percentage of intracellular ROS, whereas luminometry was used to detect the levels of intracellular glutathione (GSH), thus indicating which concentration provided a more robust defence against oxidative damage. Based on these results, $25 \mu \mathrm{M}$ resveratrol was used for all subsequent assays.

\section{CELL PREPARATION FOR ASSAYS}

Cells were incubated with the treatments for 24 and $48 \mathrm{~h}$. Treatments included a control (CCM containing the solvent vehicle, DMSO), the IC $_{50}$ values of OTA, a resveratrol control (CCM containing $25 \mu \mathrm{M}$ resveratrol), and a co-treatment ( IC $_{50}$ values of OTA and $25 \mu \mathrm{M}$ resveratrol in CCM). Cells were removed by trypsinization and agitation, the trypan blue method of cell counting was employed to determine cell viability and number as required per assay performed. The control was used for statistical comparison to all other treatments.

\section{GLUTATHIONE ASSAY}

The GSH assay [per GSH-Glo ${ }^{\mathrm{TM}}$ glutathione assay protocol (Promega)] was used to determine the concentration of GSH in HEK293 cells. Cells $\left(10^{4}\right.$ cells/well) were seeded in a luminometry plate in triplicate. Standards (0-50- $\mu \mathrm{M})$ were added in triplicate to generate a standard curve of known GSH concentrations. The GSH-Glo ${ }^{\mathrm{TM}}$ reagent $(50 \mu \mathrm{l})$ was added to each well; the plate was agitated for $30 \mathrm{~s}$, and incubated in the dark (RT, $30 \mathrm{~min}$ ). The luciferin detection reagent (100 $\mu \mathrm{l}$ ) was added to each sample and incubated as previously described (RT, $15 \mathrm{~min})$. The plates were read on a Modulus ${ }^{\mathrm{TM}}$ microplate luminometer (Turner Biosystems, Sunnyvale, CA). The GSH concentrations were determined by extrapolation from the standard curve.

\section{SINGLE CELL GEL ELECTROPHORESIS (SCGE) ASSAY}

Cells were incubated with the treatments for 24 and $48 \mathrm{~h}$, thereafter cells were removed by trypsinization and agitation, then counted; 15,000 cells were removed and resuspended in $25 \mu \mathrm{l}$ PBS. Low melting point agarose (LMPA) was used to prepare the gels. The first gel layer (700 $\mu$ l 2\% LMPA) was formed on a frosted microscope slide, covered with a coverslip, and incubated at $4{ }^{\circ} \mathrm{C}(10 \mathrm{~min})$. Thereafter, the coverslip was removed, a second gel layer (including $1.5 \mu \mathrm{l} \mathrm{GR}$ red dye, $25 \mu \mathrm{l}$ cell suspension ( $10^{4}$ cells) in $175 \mu \mathrm{l} 1 \%$ LMPA) was added, coverslips were placed over slides, and incubated as above. Coverslips were removed and a third layer was added (1\% LMPA, $200 \mu \mathrm{l}$ ) onto the second. Once the third layer solidified, coverslips were removed, slides were submerged in an ice-cold cell lysing solution [10 mM Tris ( $\mathrm{pH} 10), 1 \%$ Triton X-100, $2.5 \mathrm{M} \mathrm{NaCl}$, $100 \mathrm{mM}$ EDTA, and 10\% DMSO), and incubated in the dark $\left(4^{\circ} \mathrm{C}, 1 \mathrm{~h}\right)$. The lysing solution was removed, slides were placed in an electrophoresis tank filled with electrophoresis buffer $(300 \mathrm{mM}$ $\mathrm{NaOH}$ and $1 \mathrm{mM} \mathrm{Na}{ }_{2}$ EDTA), and allowed to equilibrate for $20 \mathrm{~min}$. The electrophoresis tank was sealed and a constant voltage was applied (25V, $35 \mathrm{~min})$. After electrophoresis, slides were washed thrice ( 5 min each) with neutralization buffer (0.4 M Tris, $\mathrm{pH} 7.4$ ). Slides were viewed using an Olympus IX5I inverted fluorescent microscope (510-560 nm excitation, $590 \mathrm{~nm}$ emission filters) using analySIS Image Processing Software (Novell). Approximately 50 comets per treatment (three replicates) were counted and analyzed by measuring tail length $(\mu \mathrm{m})$.

\section{RNA EXTRACTION}

RNA was isolated following an in-house protocol using Trizol. Trizol reagent $(500 \mu \mathrm{l})$ was added to each flask and incubated $\left(4^{\circ} \mathrm{C}, 10 \mathrm{~min}\right)$. Cells were removed from flasks, transferred to $1.5 \mathrm{ml}$ eppendorfs, and stored in Trizol at $-80^{\circ} \mathrm{C}$ overnight. Chloroform (100 $\mu$ l) was added to thawed samples and incubated (RT, $3 \mathrm{~min}$ ). Thereafter, cell suspensions were centrifuged $\left(12,000 \mathrm{~g}, 4^{\circ} \mathrm{C}, 15 \mathrm{~min}\right)$, the aqueous phase removed, $250 \mu \mathrm{l}$ isopropanol was added, and samples were left overnight at $-80^{\circ} \mathrm{C}$. Samples were thawed and centrifuged $\left(12,000 \mathrm{~g}, 4^{\circ} \mathrm{C}, 20 \mathrm{~min}\right)$. The supernatant was discarded, the pellet was retained and washed with 75\% cold ethanol (500 $\mu \mathrm{l})$, and centrifuged (7,400 $\left.\mathrm{g}, 4^{\circ} \mathrm{C}, 15 \mathrm{~min}\right)$. Ethanol was removed and samples were allowed to air dry. The pellet was resuspended in nuclease-free water $(15 \mu \mathrm{l})$ and incubated (RT, $3 \mathrm{~min})$. The RNA was quantified using the Nanodrop2000 spectrophotometer (Thermo-Scientific) and the $\mathrm{A}_{260} / \mathrm{A}_{280}$ ratio was used to assess the RNA integrity. The concentration of RNA was standardized to $2,500 \mathrm{ng} / \mu \mathrm{l}$ and used to prepare cDNA using the iScript cDNA synthesis Kit (Bio-Rad) as per manufacturer's instructions (4 $\mu$ l $5 \times$ iScript reaction mix, $1 \mu$ iScript reverse transcriptase, $11 \mu$ l nucleasefree water, and $4 \mu \mathrm{l}$ of each RNA sample).

\section{QUANTITATIVE POLYMERASE CHAIN REACTION (QPCR)}

Gene expression was analyzed using the iScript SYBR Green PCR kit (Bio-Rad), according to the manufacturer's instructions. The final reaction volume totaled $25 \mu \mathrm{l}(12.5 \mu \mathrm{l}$ SYBR Green, $1 \mu \mathrm{l}$ forward primer, $1 \mu \mathrm{l}$ reverse primer, $9 \mu \mathrm{l}$ nuclease-free water, and $1.5 \mu \mathrm{l}$ cDNA sample). All primers were obtained from Inqaba Biotec. The mRNA expressions of oxoguanine glycosylase 1 (OGG1) (forward $5^{\prime}$ GCATCGTACTCTAGCCTCCAC-3' ; reverse 5' -AGGACTTTGCTCCCTCCAC- $3^{\prime}$ ) and Nrf2 (forward 5'-AGTGGATCTGCCAACTACTC-3'; reverse 5'-CATCTACAAACGGGAATGTCTG-3') were investigated. This assay was carried out using three replicates per treatment and $\beta$-actin (forward 5'-TGACGGGTCACCCACACTGTGCCCAT-3'; reverse $5^{\prime}$-CTAGAAGCATTTGCGGTGGACGATGGAGGG-3') as a house-keeping gene. The initial denaturation occurred at $95^{\circ} \mathrm{C}(4 \mathrm{~min})$. This was followed by 37 cycles of denaturation $\left(95^{\circ} \mathrm{C} ; 15 \mathrm{~s}\right)$, annealing ( $40 \mathrm{sec}$; 0GG1 $-60^{\circ} \mathrm{C}$; $\mathrm{Nrf} 2-58^{\circ} \mathrm{C}$ ), and extension $\left(72^{\circ} \mathrm{C}\right.$; $30 \mathrm{~s}$ ). The method described by Livak and Schmittgen was employed to determine the changes in relative mRNA expression, where $2^{-\Delta \Delta C t}$ represents the fold change observed in mRNA expression [Livak and Schmittgen, 2001].

\section{SDS -POLYACRYLAMIDE GEL ELECTROPHORESIS (SDS-PAGE) AND WESTERN BLOTTING}

Crude protein was isolated from cells using Cytobuster ${ }^{\mathrm{TM}}$ (Novagen) supplemented with protease inhibitors (Roche 05892791001) and phosphatase inhibitors (04906837001). Cytobuster reagent (250 $\mu \mathrm{l})$ was added to flasks following treatments; the cells were scraped and transferred to a $1.5 \mathrm{ml}$ tube and incubated on ice (10 min). The cell solution was centrifuged $\left(10,000 \mathrm{~g}, 4^{\circ} \mathrm{C}, 5 \mathrm{~min}\right)$. The supernatant was used for protein quantification using the bicinchoninic acid (BCA) assay. Bovine serum albumin (BSA) standards $(0-1 \mathrm{mg} / \mathrm{ml})$ were prepared. Samples and standards $(25 \mu \mathrm{l})$ were pipetted into a 96-well 
microtiter plate in duplicate. The BCA reagent was prepared (198 $\mu \mathrm{l}$ BCA: $4 \mu \mathrm{CuSO}_{4}$ per reaction) and $200 \mu \mathrm{l}$ of this working solution was added to each well. After incubation $\left(37^{\circ} \mathrm{C}, 30 \mathrm{~min}\right)$, the absorbance was read on a Bio-Tek MQx200 spectrophotometer at $562 \mathrm{~nm}$. A standard curve was constructed and proteins were standardized to $1 \mathrm{mg} / \mathrm{ml}$. Laemmli buffer [dH20, 0.5 M Tris- $\mathrm{HCl}(\mathrm{pH}$ 6.8), glycerol, $10 \%$ SDS, $\beta$-mercaptoethanol, $1 \%$ bromophenol blue] was added to each sample (1:1, total volume $200 \mu \mathrm{l})$, and heated to $100{ }^{\circ} \mathrm{C}$ ( $5 \mathrm{~min}$ ). Samples were separated on SDS polyacrylamide gel (7.5\% resolving gel and 4\% stacking gel) for $1 \mathrm{~h}$ at $150 \mathrm{~V}$, and transferred onto nitrocellulose membranes using the Transblot ${ }^{\circledR}$ Turbo $^{\text {TM }}$ Transfer system (Bio-Rad). Membranes were blocked with 3\% BSA in Tris-buffered saline [TTBS, 25 mM Tris (pH 7.6) $150 \mathrm{mM}$ $\mathrm{NaCl}, 0.05 \%$ Tween 20] for $30 \mathrm{~min}$, and incubated with a primary antibody $\left(1: 1,000,3 \%\right.$ BSA in TTBS at $4{ }^{\circ} \mathrm{C}$ overnight). Antibodies used were anti-Nrf2 (8882), anti-phospo SIRT1 (2314L), anti-SIRT3 (C73E7), and anti-LonP1 (HPA002192-100UL). Protein concentrations were standardized to anti- $\beta$-actin (Sigma-Aldrich A3854). After incubation, the primary antibody was removed, membranes were washed thrice with TTBS (10 min), and incubated with a horseradish peroxidase (HRP)-conjugated secondary antibody (SantaCruz Biotechnology, Inc.) in 3\% BSA $(1: 10,000)$ for $1 \mathrm{~h}$. Following incubation, membranes were washed with TTBS. Clarity Western ECL Substrate (Bio-Rad) $(400 \mu \mathrm{l})$ was added to the membranes and images were captured using a gel documentation system (UviTech Alliance 2.7). The membranes were then quenched with hydrogen peroxide, incubated in a blocking solution (3\% BSA, $1 \mathrm{~h}, \mathrm{RT}$ ), rinsed twice in TTBS, and probed with HRP-conjugated anti$\beta$-actin (house-keeping protein) (Sigma). Densitometry analysis was performed using the UviTech Analysis software and protein expression was read as relative band intensity (Arbillaga et al., 2007). Protein expression was reported as RBI of the protein of interest divided by the RBI of the loading control.

\section{FLOW CYTOMETRY - INTRACELLULAR REACTIVE OXYGEN SPECIES (ROS)}

Treated cells were removed and counted, 500,000 cells were required per treatment. Cells were incubated in phenol red-free media, supplemented with 10\% FCS and $10 \mu \mathrm{M}$ dichlorodihydrofluorescein diacetate (DCFDA), in the dark $\left(45 \mathrm{~min}, 37^{\circ} \mathrm{C}\right)$. Thereafter, cells were rinsed thrice with $0.1 \mathrm{M}$ PBS and centrifuged ( $400 \mathrm{~g}$, RT, $5 \mathrm{~min}$ ), then suspended in $150 \mu \mathrm{l} 0.1 \mathrm{M}$ PBS and analyzed using a BD Accuri ${ }^{\mathrm{TM}}$ flow cytometer. Live cells were gated and analyzed using CFlow Plus Software (BD Biosciences).

\section{STATISTICAL ANALYSIS}

Statistical analyses were performed using a one-way analysis of variance (ANOVA) test and the Students' $t$-test, using GraphPad Prism version 5.0 (GraphPad Software, San Diego, CA). All data are expressed as mean \pm standard error. All assays were run in triplicate and differences were considered statistically significant at values of ${ }^{*} P<0.05$.

\section{Results}

\section{MTT ASSAY}

The MTT assay was used to determine the $\mathrm{IC}_{50}$ value of OTA during 24-h incubation $(1.5 \mu \mathrm{M})$ and 48 -h incubation $(9.4 \mu \mathrm{M})$ in HEK293 cells (Fig. 1). The $\mathrm{IC}_{50}$ values were used for all subsequent assays.

\section{RESVERATROL DECREASES INTRACELLULAR ROS PRODUCTION DURING 24-H EXPOSURE}

Flow cytometry was used to measure intracellular ROS production in HEK293 cells. Resveratrol significantly reduced intracellular ROS in the kidney cells from $47.7 \%$ to $20.2 \%$ (Fig. $2 \mathrm{~A} ; P<0.0001$ ). Both the OTA (25.3\%) and OTA+resveratrol (28.9\%) treatments significantly reduced ROS when compared to control cells (47.7\%) (Fig. 2; $P=0.0048$ ). The opposite was observed during the 48-h exposure, where all treatments increased the intracellular ROS when compared to control cells. A significant increase was observed when cells were exposed to 0TA+resveratrol over $48 \mathrm{~h}$ (Fig. $2 ; P=0.0002$ ).

\section{ASSESSMENT OF DNA DAMAGE AND REPAIR}

OTA-treated cells $(24 \mathrm{~h})$ had significantly longer comet tails $(44.82 \pm 1.516 \mu \mathrm{m} ; P<0.0001)$ as compared to the control cells (Fig. 3B). In contrast, resveratrol significantly decreased comet tail lengths compared to all other treatments $(11.69 \pm 0.695 \mu \mathrm{m}$; $P<0.0001)$. Interestingly, cells co-treated with 0TA+resveratrol also showed significantly decreased comet tail lengths as compared
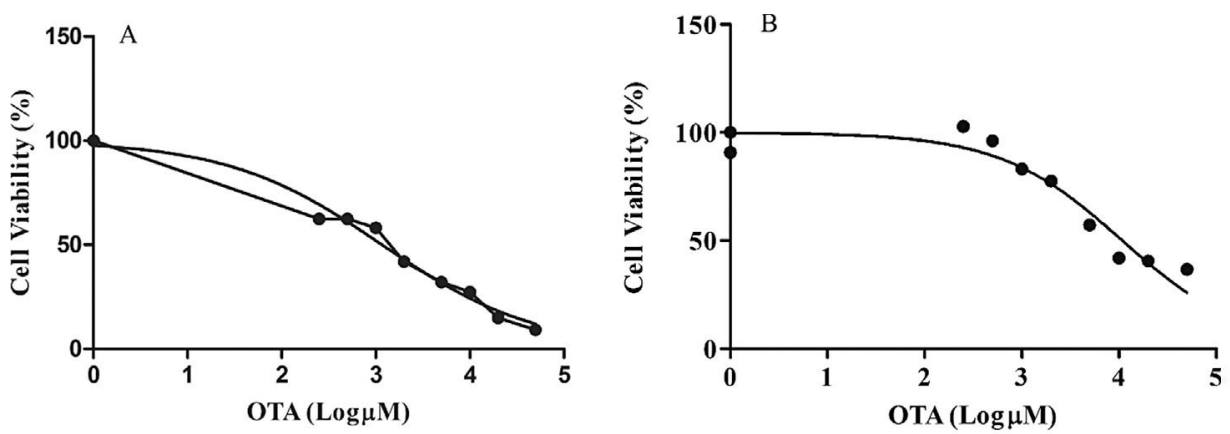

Fig. 1. Percentage viability of cells exposed to OTA over (A) $24 \mathrm{~h}$ and (B) $48 \mathrm{~h}$. An IC 50 of $1.5 \mu \mathrm{M}(24 \mathrm{~h}$ ) and $9.4 \mu \mathrm{M}$ (48 h) was calculated from the dose-response curves. 


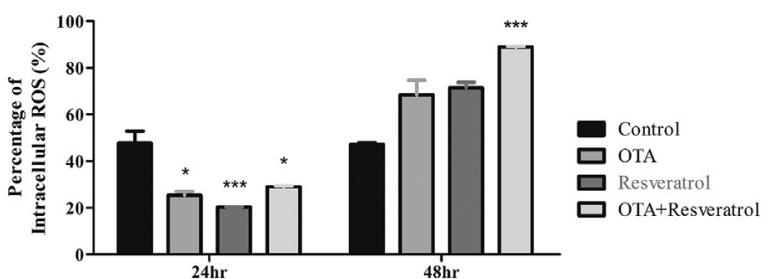

Fig. 2. Assessment of the percentage of intracellular ROS in cells exposed to OTA and resveratrol over 24 and $48 \mathrm{~h}$. Resveratrol significantly decreased the percentage of intracellular ROS $\left({ }^{* * *} P<0.0001\right)$, whereas OTA and OTA+resveratrol treatments decreased the values of ROS when compared to control cells during 24-h exposure $\left({ }^{*} P=0.0048\right)$. Upon 48-h exposure, OTA+resveratrol significantly increased the ROS values $\left({ }^{* * *} P=0.0002\right)$, whereas the OTA and resveratrol treatments also increased intracellular ROS.

A)
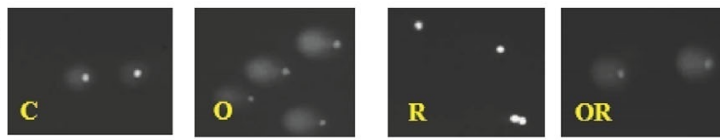

B)

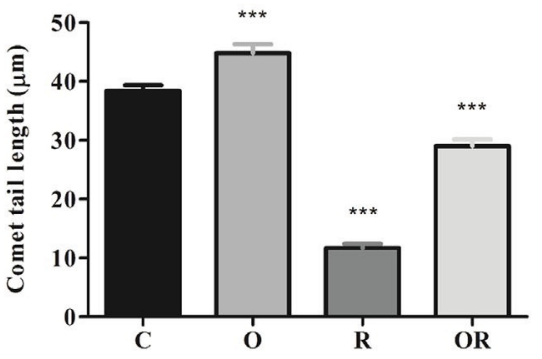

C)
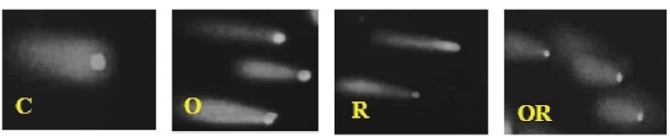

D)

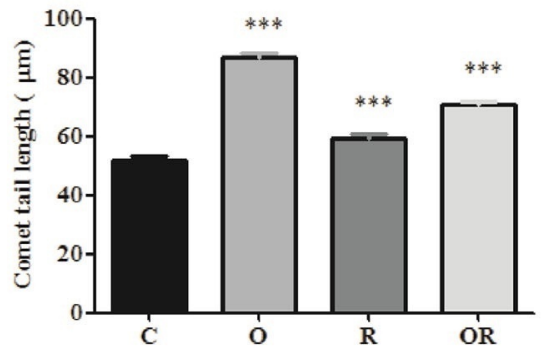

Fig. 3. Assessment of DNA damage showing images of (A) comet tails during 24- $h$ exposure, (B) the measurement of comet tail lengths during 24-h exposure, (C) comet tails during 48-h exposure, and (D) the measurement of comet tail lengths during 48-h exposure. OTA increased comet tail lengths during both exposure time periods ( ${ }^{* * *} P<0.0001$ ). Comet tail lengths doubled during the 48-h exposure. The OTA+Resveratrol co-treatment significantly decreased lengths compared to cells only treated with OTA ( $\left.{ }^{* * *} P<0.0001\right)$. to cells only exposed to OTA (Fig. 3B; $29.03 \pm 1.110 \mu \mathrm{m}$ vs. $44.82 \pm 1.516 \mu \mathrm{m} ; P<0.0001)$. These observations were similar for the 48-h exposure period; however, the comet tails almost doubled in length. OTA-treated cells ( $48 \mathrm{~h}$ ) had significantly longer comet tails $(86.67 \mu \mathrm{m})$ as compared to the 24-h treatment (44.82 $\mu \mathrm{m})$ (Fig. 3D). In addition, the comet tails were brighter and longer in OTA-treated cells, indicating that more DNA activity and increased DNA strand breaks occurred with increased exposure. The co-treatment (OTA+resveratrol) significantly decreased comet tail lengths compared to OTA-treated cells (Fig. 3D; 70.72 $\pm 1.030 \mu \mathrm{m}$ vs. $86.67 \pm 1.694 \mu \mathrm{m} ; P<0.0001)$.

\section{MEASUREMENT OF GSH CONCENTRATIONS}

Intracellular concentration of GSH was determined using luminometry. GSH concentrations in HEK293 cells were significantly increased by OTA+resveratrol treatment as compared to OTAtreated cells $(P<0.05)$; however, this concentration doubled after 48-h exposure $(P<0.001)$ (Fig. 4). The co-treatment of cells with OTA+resveratrol yields increased concentrations of GSH than in cells exposed to OTA alone. Generally, the GSH concentrations are far higher over 48-h exposure times than 24-h exposures (Fig. 4). The concentration of GSH was seen to decrease in OTA-treated cells compared to controls, thus indicating that longer exposure to OTA could deplete the antioxidant defence of the cells, allowing ROS to overrun the cell.

\section{OPCR ANALYSIS OF ANTIOXIDANT RESPONSE}

The mRNA expression of Nrf2 and OGG1 was assessed by qPCR. The expression of Nrf2, an antioxidant defence regulator, was significantly decreased by OTA, resveratrol, and OTA+resveratrol after 24-h exposure (Fig. 5A; $P<0.05$ ); Nrf2 expression decreased further after $48 \mathrm{~h}$ (Fig. 5B). Resveratrol increased the expression of OGG1 $(P<0.05)$, whereas the co-treatment significantly decreased its expression after $24 \mathrm{~h}$ (Fig. 5C; $P<0.05$ ). The co-treatment, however, significantly increased OGG1 expression when measured after $48 \mathrm{~h}$ (Fig. 5D; $P<0.05$ ).

\section{WESTERN BLOTTING}

The protein expression of Nrf2, LonP1, SIRT3, and pSIRT1 was determined using Western blot. Nrf2 protein expression was

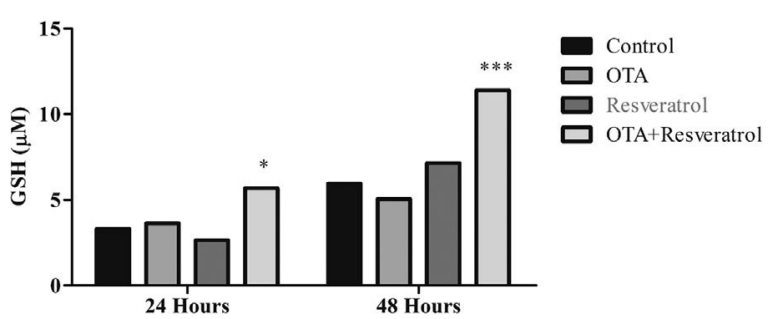

Fig. 4. Concentrations of GSH in HEK293 cells after exposure to OTA and resveratrol. The OTA+resveratrol co-treatment increased the concentrations of GSH during the 24-h exposure compared to GSH present in OTA-treated cells ( $P<0.05$ ). The co-treatment also increased GSH during the $48-\mathrm{h}$ exposure (*** $P<0.001)$. 

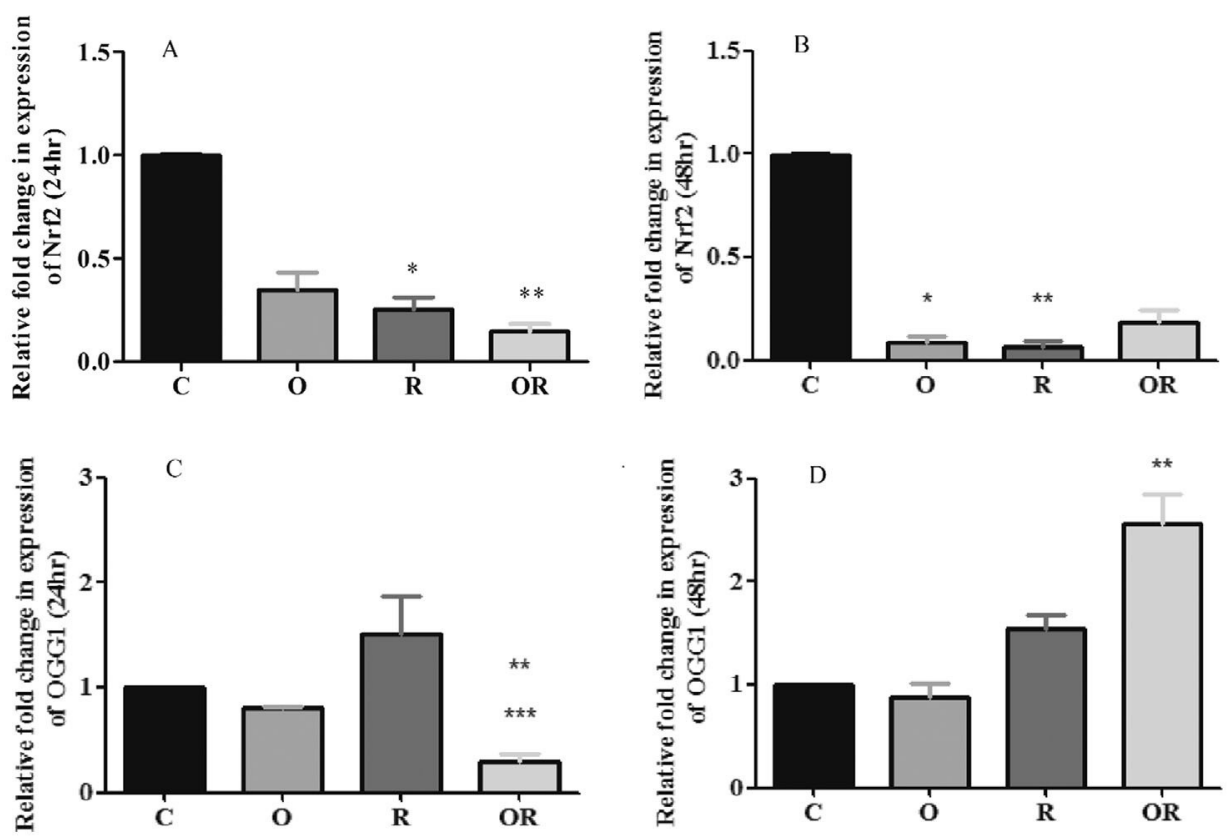

\begin{abstract}
Fig. 5. Analysis of the mRNA expression of genes associated with cellular protection. Nrf2 expression was seen to decrease upon exposure to $0 \mathrm{TA}$, resveratrol ( $P<0.05)$, and OTA+Resveratrol ( $\left.{ }^{* *} P=0.001\right)$ for $24 \mathrm{~h}$. (B) The expression of Nrf2 was seen to decrease further when exposed to 0 TA ( $\left.{ }^{*} P<0.05\right)$ and resveratrol $\left({ }^{* *} P=0.0021\right)$ for $48 \mathrm{~h}$. The DNA glycosylase enzyme, $0 G G 1$, was observed to increase during $24-\mathrm{h}$ resveratrol exposure and significantly decrease during exposure to 0 TA+resveratrol (** $P<0.05$ ) for $24 \mathrm{~h}$. (C) OGG1 expression was significantly decreased during OTA+resveratrol exposure compared to resveratrol-treated cells ( ${ }^{* * *} P=0.0002$ ).(D) Recovery of $0 \mathrm{GG1}$ expression was observed during 48-h exposure to OTA+resveratrol ( $\left.{ }^{* *} P<0.05\right)$.
\end{abstract}

decreased by all treatments after 24-h exposure, significantly by OTA + resveratrol $(P<0.05)$, but increased by 0TA $(P<0.05)$ and resveratrol $(P<0.0008)$ after $48 \mathrm{~h}$. An inverse relationship was found to exist between SIRT3 and LonP1 after $24 \mathrm{~h}$, SIRT3 decreased and LonP1 increased. Resveratrol increased SIRT3 $(P<0.05)$ and LonP1 $(P=0.0005)$ expression $(48 \mathrm{~h})$, and pSIRT1 at both time periods ( $P=0.0002$ and $P=0.0054$, respectively) (Fig. 6).

\section{Discussion}

OTA is a mycotoxin that frequently contaminates a wide range of foods. Once ingested, OTA exerts its toxic effects via several pathways. One such pathway in the kidney is increased oxidative stress, resulting in DNA damage and progressive renal failure in individuals who chronically ingest foods contaminated with high concentrations of OTA [Pfohl-Leszkowicz and Manderville, 2007]. OTA poses a health risk to populations in developing countries, as they depend largely on agricultural crops often heavily contaminated with fungi, such as Aspergillus and Penicillium [Castegnaro et al., 2006]. OTA has been identified as an etiological agent in BEN [Castegnaro et al., 2006]. The exact mechanism of OTA toxicity is still relatively unknown, although many mechanisms have been proposed. The general trend of reduced antioxidant defense capacity has been documented in different cell lines, such as the normal rat kidney (NRK) epithelial cells [Schilter et al., 2005; Cavin et al., 2007].
In this study, we provide insight into the biochemical changes induced by OTA in human embryonic kidney (HEK293) cells.

Resveratrol, a phytoalexin, possesses antioxidant characteristics, chemopreventive potential, and has been proposed as a treatment for illnesses, such as diabetes, cancer, and cardiovascular disease [Rossi et al., 2012]. Our study determined whether resveratrol could reduce/ prevent OTA-induced cytotoxicity in kidney cells. Our aim was to determine whether resveratrol could prevent cytotoxicity induced by OTA in kidney cells. Under normal conditions, ROS regulates intracellular signaling; however, under conditions of excessive ROS production, intracellular signaling is compromised and will result in cellular damage [Wang et al., 2013]. Excessive oxidative stress induces cytotoxicity and alters cellular functioning [Weydert and Cullen, 2010]. Lipids, proteins, and DNA are susceptible to ROS attack and subsequent damage [Marin-Kuan et al., 2011].0TA decreased intracellular ROS (as determined by FACS), but still induced single strand DNA breaks (comet assay). Exposure to OTA $(24 \mathrm{~h}, 1.5 \mu \mathrm{M})$ resulted in significant DNA strand breaks in HEK293 cells, suggesting that OTA is genotoxic. In comparison to control cells, OTA significantly increased the lengths of comet tails by $16.8 \%$, whereas resveratrol significantly decreased comet tail lengths by $69.5 \%$ (Fig. 3). Resveratrol also significantly reduced OTA genotoxicity as the co-treatment decreased DNA tail lengths (35.2\%). In addition, the intracellular ROS was the lowest in resveratrol-treated cells (20.2\%). When DNA damage occurs, the cell activates DNA repair enzymes, such as OGG1-a DNA glycosylase 


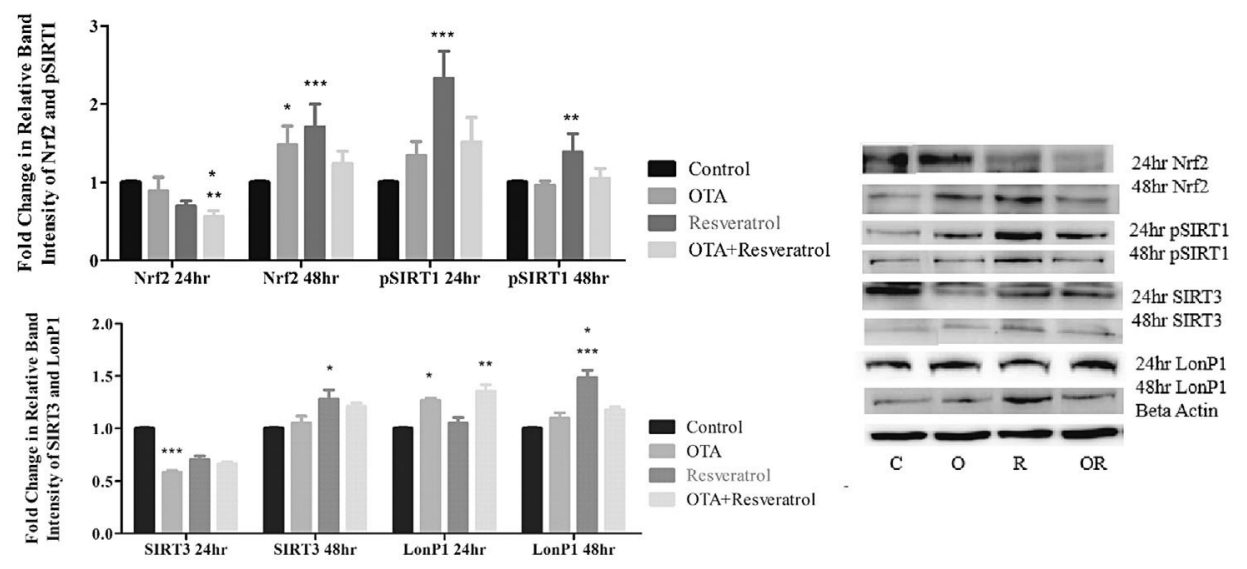

Fig. 6. Western blot images and relative fold change in protein expression of Nrf2, pSIRT1, SIRT3, and LonP1 over 24 and $48 \mathrm{~h}$, in response to OTA and resveratrol exposure. Resveratrol decreases Nrf2 expression during 24-h exposure, but increases Nrf2 during 48-h exposure ( ${ }^{* * *} P<0.0008$ ). 0TA significantly increased Nrf2 expression during 48-h exposure ( $\left.{ }^{*} P<0.05\right)$. The 0TA+resveratrol co-treatment significantly decreased Nrf2 expression during $24-\mathrm{h}$ exposure $\left({ }^{*} P<0.05\right)$. Resveratrol significantly increased the expression of pSIRT1 during $24-\mathrm{h}$ exposure $\left({ }^{* * *} P=0.0002\right)$ and $48-\mathrm{h}$ exposure $\left({ }^{* *} \boldsymbol{P}=0.0054\right)$. SIRT3 expression decreased in all treatments during $24-\mathrm{h}$ exposure with a significant decrease during OTA exposure ( ${ }^{* * *} P=0.0003$ ). The opposite was observed during $48-\mathrm{h}$ exposure, all treatments increased SIRT3 expression with significance in the resveratrol treatment $\left({ }^{*} P<0.05\right)$. LonP1 expression exhibits the inverse of SIRT3 expression, with an increase in LonP1 expression during $24-\mathrm{h}$ exposure to $0 \mathrm{TA}\left({ }^{*} P<0.05\right)$ and OTA+Resveratrol ( $\left.{ }^{* *} P=0.0011\right)$. LonP1 expression increased significantly upon 48 -h exposure to resveratrol $\left({ }^{* * *} P=0.0005\right)$.

enzyme, which removes 8-oxoguanine base lesions, that could result in mutations and carcinogenesis if left to accumulate [Cheng et al., 2013]. The OTA decreased expression of OGG1 and increased DNA tail lengths. This suggests that OGGI enzyme activity is compromised and as a consequence, base lesions persist. However, resveratrol increased OGG1 expression in kidney cells, resulting in significantly shorter DNA tail lengths, whereas the co-treatment, although inducing low expression of OGG1, significantly decreased DNA tail lengths. In the co-treatment, resveratrol afforded a protective function, due to its antioxidant properties, by decreasing intracellular ROS and increasing OGG1 expression. This may explain its cyto-protective and potential anti-cancer property. The 48-h ROS results differ, in that all treatments show increased intracellular ROS (Fig. 2) and a concomitant significant increase in OGG1 expression and shorter comet tails. This suggests that resveratrol aided the cells to survive in response to OTA toxicity.

Palma et al. (2007) showed that OTA induced DNA damage by increasing the production of free radicals. Our data are in agreement with this study as demonstrated by the comet and flow cytometry ROS assays.

GSH, a low molecular weight thiol found abundantly in cells, is a potent endogenous antioxidant [Wu et al., 2004]. GSH depletion indicates an increase in ROS and oxidative stress. OTA severely depleted GSH concentrations $(5.06 \mu \mathrm{M})$ in kidney cells, whereas resveratrol increased GSH $(2.65 \mu \mathrm{M}$ at $24 \mathrm{~h} ; 7.14 \mu \mathrm{M}$ at $48 \mathrm{~h})$. Further in the co-treated cells, resveratrol significantly increased GSH from $5.68 \mu \mathrm{M}(24 \mathrm{~h})$ to $11.39 \mu \mathrm{M}(48 \mathrm{~h})$. These results indicate that resveratrol increases the antioxidant capacity of the cell over longer periods of time by increasing GSH synthesis. In addition, resveratrol clearly shows its potent antioxidant capacity by dampening the effects of OTA induced toxicity in kidney cells.
At both 24- and 48-h treatment periods, Nrf2 mRNA expression was significantly decreased. Nrf2 expression was lowest at $24 \mathrm{~h}$ but higher at $48 \mathrm{~h}$ in the co-treated cells. Although resveratrol induced low expression of Nrf2 compared to other treatments, the concentrations of GSH were significantly increased and DNA tail lengths were shorter. Taken together, our data show that resveratrol is a potent antioxidant that can function independently in the cell without influence from Nrf2. OTA induced a non-significant increase in Nrf2 expression with increased DNA damage, high ROS levels, and lower GSH concentrations.

Western blot protein analysis revealed changes in Nrf2 expression over the two treatment periods; at $24 \mathrm{~h}$, all treatments decreased Nrf2 expression, wheres at $48 \mathrm{~h}$, Nrf2 expression was increased. The decreased Nrf2 expression strongly suggests that resveratrol itself mediates the antioxidant defense response, in keeping with its antioxidant properties [Momchilova et al., 2014]. The protein and mRNA expression of Nrf2 at $24 \mathrm{~h}$ is in agreement; however, these results are different at $48 \mathrm{~h}$. The mRNA expression of Nrf2 is significantly decreased, but the protein expression is significantly increased. This result could be due to alterations in post-translational modifications or the increased expression of LonP1. LonP1, a protease, is known for its regulatory function and could assist in degrading potentially compromised proteins [Bota et al., 2002].

SIRT3 has been identified as a regulator of LonP1 expression; increased SIRT3 decreases LonP1 [Gibellini et al., 2014]. This inverse relationship is clearly evident at $24 \mathrm{~h}$-decreased SIRT3 and increased LonP1 expression. A significant increase in LonP1 and decreased SIRT3 expression was observed in OTA and cotreated kidney cells. The increased expression of LonP1 is triggered by increased oxidative stress to combat accumulation of defective 
proteins. This mitochondrial protease could have acted in a compensatory manner by degrading proteins damaged by oxidative stress [Zhang et al., 2014].

SIRT1, a NAD ${ }^{+}$-dependent deacetylase, is activated by resveratrol. In our study, resveratrol increased SIRT1 expression in cells at both 24 and $48 \mathrm{~h}$. Activated SIRT1 by phosphorylation influences many processes, such as DNA repair and cellular metabolism, thereby impacting the cellular stress response. Phosphorylated SIRT1 increases nuclear localization of the protein, as well as increased enzymatic activity [Sasaki et al., 2008]. The stress protection pathway is mediated by SIRT1, increased phosphorylation would influence this function, and induce possible deacetylation of stress proteins, such as p53 and PGC-1 $\alpha$, causing cellular protection and survival [Nasrin et al., 2009].

These data provide insight into the behavior of OTA, as well as the therapeutic potential of resveratrol. We are proposing that short-term effects of OTA contribute to its toxicity. The cells experience an increase in the antioxidant response due to the recognition of a cytotoxic environment; however, it is not possible to sustain an increased protective response while DNA damage occurs. This is evidenced by the 48-h data, as the time period progresses, so too does the extent of damage inflicted on the cell by the toxin. Our data suggest that OTA exhausts the cell's antioxidant reservoir during acute exposure, and thus the cell is left vulnerable as the exposure period continues. Taken together, theses data suggest that resveratrol could be a potential treatment for OTA toxicity, as well as a possible therapy for other oxidative stress-inducing toxins. Regarding the information on DNA damage prevention, this research also attests to the chemopreventive potential of resveratrol.

\section{References}

Arbillaga L,Azqueta A, Ezpeleta 0, Lopez de Cerain A. 2007. Oxidative DNA damage induced by ochratoxin A in the HK-2 human kidney cell line: Evidence of the relationship with cytotoxicity. Mutagenesis 22:35-42.

Athar M, Back JH, Tang X, Kim KH, Kopelovich L, Bickers DR, Kim AL. 2007. Resveratrol: A review of preclinical studies for human cancer prevention. Toxicolo Appl Pharmacol 224:274-283.

Bankole S, Schollenberger M, Drochner W. 2006. Mycotoxins in food systems in Sub Saharan Africa: A review. Mycotoxin Res 22:163-169.

Baur JA, Sinclair DA. 2006. Therapeutic potential of resveratrol: The in vivo evidence. Nat Rev Drug Discov 5:493-506.

Borra MT, Smith BC, Denu JM. 2005. Mechanism of human SIRT1 activation by resveratrol. J Biol Chem 280:17187-17195.

Bota DA, Van Remmen H, Davies KJA. 2002. Modulation of Lon protease activity and aconitase turnover during aging and oxidative stress. FEBS Lett 532:103-106.

Castegnaro M, Canadas D, Vrabcheva T, Petkova-Bocharova T, Chernozemsky IN, Pfohl-Leszkowicz A. 2006. Balkan endemic nephropathy: Role of ochratoxins A through biomarkers. Mol Nutr Food Res 50:519-529.

Cavin C, Delatour T, Marin-Kuan M, Holzhauser D, Higgins L, Bezencon C, Guignard G, Junod S, Richoz-Payot J, Gremaud E. 2007. Reduction in antioxidant defenses may contribute to ochratoxin A toxicity and carcinogenicity. Toxicol Sci 96:30-39.

Cheng Y, Ren X, Gowda AS, Shan Y, Zhang L, Yuan Y-S, Patel R, Wu H, Huber-Keener K, Yang JW. 2013. Interaction of Sirt3 with OGG1 contributes to repair of mitochondrial DNA and protects from apoptotic cell death under oxidative stress. Cell Death \& Disease 4.

Gibellini L, Pinti M, Beretti F, Pierri CL, Onofrio A, Riccio M, Carnevale G, De Biasi S, Nasi M, Torelli F. 2014. Sirtuin 3 interacts with Lon protease and regulates its acetylation status. Mitochondrion 18:76-81.

Hohler D, Sudekum KH, Wolffram S, Frohlich AA, Marquardt RR. 1999. Metabolism and excretion of ochratoxin A fed to sheep. J Anim Sci 77:12171223.

Jonsyn-Ellis F 2012. Ochratoxin A: Any cause for concern in Sub Saharan Africa? Sci J Environ Eng Res 2012:5.

Livak KJ, Schmittgen TD. 2001. Analysis of relative gene expression data using real-time quantitative PCR and the 2(-Delta Delta C(T)) method. Methods 25:402-408.

Marin-Kuan M, Cavin C, Delatour T, Schilter B. 2008. Ochratoxin A carcinogenicity involves a complex network of epigenetic mechanisms. Toxicon 52:195-202.

Marin-Kuan M, Ehrlich V, Delatour T, Cavin C, Schilter B. 2011. Evidence for a role of oxidative stress in the carcinogenicity of ochratoxin A. Journal of Toxicology 2011.

Meyer JN, Leung MCK, Rooney JP, Sendoel A, Hengartner MO, Kisby GE, Bess AS. 2013. Mitochondria as a target of environmental toxicants. Toxicol Sci 134:1-17.

Momchilova A, Petkova D, Staneva G, Markovska T, Pankov R, Skrobanska R, Nikolova-Karakashian M, Koumanov K. 2014. Resveratrol alters the lipid composition, metabolism and peroxide level in senescent rat hepatocytes. Chem Biol Interact 207:74-80.

Nasrin N, Kaushik VK, Fortier E, Wall D, Pearson KJ, de Cabo R, Bordone L. 2009. JNK1 phosphorylates SIRT1 and promotes its enzymatic activity. PLoS One 4:e8414.

Nguyen T, Nioi P, Pickett CB. 2009. The Nrf2-antioxidant response element signaling pathway and its activation by oxidative stress. J Biol Chem 284:13291-13295.

Özçelik N, Soyöz M, Kılınç İ. 2004. Effects of ochratoxin a on oxidative damage in rat kidney: Protective role of melatonin. J Appl Toxicol 24:211215.

Palma N, Cinelli S, Sapora 0, Wilson SH, Dogliotti E. 2007. Ochratoxin Ainduced mutagenesis in mammalian cells is consistent with the production of oxidative stress. Chem Res Toxicol 20:1031-1037.

Pfohl-Leszkowicz A, Manderville RA. 2007. Ochratoxin A: An overview on toxicity and carcinogenicity in animals and humans. Mol Nutr Food Res 51:61-99.

Rossi D, Guerrini A, Bruni R, Brognara E, Borgatti M, Gambari R, Maietti S, Sacchetti G. 2012. Trans-Resveratrol in nutraceuticals: Issues in retail quality and effectiveness. Molecules 17:12393-12405.

Sasaki T, Maier B, Koclega KD, Chruszcz M, Gluba W, Stukenberg PT, Minor W, Scrable H. 2008. Phosphorylation regulates SIRT1 function. PLoS One 3: e4020.

Schaaf GJ, Nijmeijer SM, Maas RF, Roestenberg P, de Groene EM, FinkGremmels J. 2002. The role of oxidative stress in the ochratoxin Amediated toxicity in proximal tubular cells. Biochim Biophys Acta 1588:149-158.

Schilter B, Marin-Kuan M, Delatour T, Nestler S, Mantle P, Cavin C. 2005. Ochratoxin A: Potential epigenetic mechanisms of toxicity and carcinogenicity. Food Addit Contam 22:88-93.

Timmers S, Auwerx J, Schrauwen P. 2012. The journey of resveratrol from yeast to human. Aging 4:146-158.

van der Merwe KJ, Steyn PS, Fourie L, Scott DB, Theron JJ. 1965. Ochratoxin A, a toxic metabolite produced by Aspergillus ochraceus Wilh. Nature 205:1112-1113.

Visconti A, Perrone G, Cozzi G, Solfrizzo M. 2008. Managing ochratoxin A risk in the grape-wine food chain. Food Addit Contam 25:193-202. 
Wang CH, Wu SB, Wu YT, Wei YH. 2013. Oxidative stress response elicited by mitochondrial dysfunction: Implication in the pathophysiology of aging. Exp Biol Med 238:450-460.

Weydert CJ, Cullen JJ. 2010. Measurement of superoxide dismutase, catalase and glutathione peroxidase in cultured cells and tissue. Nat Protoc 5:51-66.
Wu G, Fang YZ, Yang S, Lupton JR, Turner ND. 2004. Glutathione metabolism and its implications for health. J Nutr 134:489-492.

Zhang B, Shen XL, Liang R, Li Y, Huang K, Zhao C, Luo Y, Xu W. 2014. Protective role of the mitochondrial Lon protease 1 in ochratoxin A-induced cytotoxicity in HEK293 cells. J Proteomics 101:154-168. 